\title{
Estudio teórico para el tratamiento de la enfermedad de Alzheimer con terapia combinada: desarrollo e innovación.
}

\author{
Carolina Guerrero-Amelín ${ }^{\mathbf{a}}$, Samuel Takvorb ${ }^{\mathbf{b}}$, Jesús Frutos ${ }^{\mathbf{c}}$, Víctor Lombardo ${ }^{\mathbf{d}}$ \\ Departamento de Biología de Sistemas, Universidad de Alcalá. 28871, Alcalá de Henares, Madrid. España. \\ a. carolina.guerreroa@edu.uah.es b.stm.97@hotmail.com c. jefrudi@hotmail.es d. victorlombardo20@gmail.com \\ V Congreso de Señalización Celular, SECUAH 2020 \\ Departamento de Biología de Sistemas, Facultad de Medicina, Universidad de Alcalá (UAH). Alcalá de \\ Henares, Madrid (Spain)
}

Palabras clave: High Throughput Screening (HTS); Enfermedad Neurodegenerativa de Alzheimer; Desarrollo farmacológico; Terapia combinada; RTN-3

\section{Resumen}

Las enfermedades neurodegenerativas suponen un gran problema de manera global, no existiendo tratamientos efectivos para su tratamiento. Estas enfermedades generalmente se encuentran ligadas a la edad, siendo uno de los principales factores de riesgo de estas. Cada vez nos encontramos con una población más envejecida globalmente gracias a los avances en Medicina, y la prevalencia de estas patologías aumenta a un ritmo desorbitado. Una de las principales enfermedades dentro de este grupo es el Alzheimer. Esta patología supone un gran costo social (por la incapacidad que produce) y sanitario (por el cuidado y tratamiento de estos pacientes) y algunos autores la consideran la gran pandemia del siglo XXI (con 5-7 millones de nuevos casos al año y 44 millones de personas afectadas). El Alzheimer afecta al SNC, caracterizada por la pérdida de sinapsis y de memoria de forma progresiva. Sin embargo, el mayor problema actual es que no existen técnicas que nos ayuden al diagnóstico precoz ni se conoce su etiología. Pese a que se han planteado numerosas hipótesis para explicar su origen (destacando la hipótesis Tau, amiloide y colinérgica), ninguna de ellas ha podido explicar la etiopatogenia real de la enfermedad. Tras un estudio exhaustivo de las vías y rutas de señalización implicadas en el Alzheimer, nuestro grupo ha decidido, de manera totalmente novedosa, abordar el tratamiento de esta enfermedad desde dos puntos distintos, realizando un estudio teórico del resultado de la terapia combinada y presentando el diseño experimental a seguir para el desarrollo de un nuevo fármaco que ayude a estos pacientes. Nuestra estrategia es el diseño de péptidos análogos al reticulón 3 (RTN-3), el cual es una proteína poco estudiada cuya función es la unión a la $\beta$-secretasa (BACE-1, responsable de la formación de las placas amiloides que dañan el tejido neuronal y que se encuentra sobreexpresada en esta patología) e inhibirla. La otra protagonista de la terapia combinada es una molécula inhibidora de GSK-3ß de forma ATP no competitiva (enzima causante de la fosforilación de Tau y su agregación, formando los ovillos neurofibrilares característicos del Alzheimer). En nuestro trabajo se muestra detalladamente el proceso de cribado (High Throughput Screening) a seguir, con todas las técnicas a emplear, para el desarrollo del péptido análogo al RTN-3, de manera totalmente científica, documentada y analizada tras revisar la literatura, aplicando técnicas de Biología celular, molecular y ensayos en animales, presentando los resultados esperados de manera teórica, y mostrando el proceso de selección de líneas celulares, modelos animales, técnicas, instrumentos y moléculas de forma veraz y totalmente análoga a la realidad.

Cita: Guerrero-Amelín, Carolina; Takvor, Samuel; Frutos, Jesús; Lombardo, Víctor (2020) Estudio teórico para el tratamiento de la enfermedad de Alzheimer con terapia combinada: desarrollo e innovación. Actas del V Congreso de Señalización Celular, SECUAH 2020. Departamento de Biología de Sistemas, Facultad de Medicina, Universidad de Alcalá (UAH). Alcalá de Henares, Madrid (Spain). dianas 9 (1): e202003fa03. ISSN 1886-8746 (electronic) journal.dianas.e202003fa03 http://www3.uah.es/dianas?e202003fa03.

URI http://hdl.handle.net/10017/15181

Copyright: @ Guerrero-Amelín C, Takvor S, Frutos J, Lombardo V. Algunos derechos reservados. Este es un artículo open-access distribuido bajo los términos de una licencia de Creative Commons ReconocimientoNoComercial-SinObraDerivada 4.0 Internacional. http://creativecommons.org/licenses/by-nc-nd/4.0/

\section{Introducción}

La enfermedad del Alzhéimer (EA) es la principal enfermedad neurodegenerativa más prevalente, siendo la causa más común en demencia y diagnosticada en el $80 \%$ de los casos de demencia [1]. Existen diferentes factores que influyen en el desarrollo de demencia, conllevando a su evolución hacia EA; como, por ejemplo, tabaquismo, hipertensión, estilo de vida; pero los factores principales son la predisposición genética, el estrés y la edad, cuya incidencia aumenta en la población mayor de 65 años, afectando más a las mujeres que a los hombres [2]. 


\section{Fisiopatología}

Se han determinado varías hipótesis a través de las cuales se plantea este trastorno multifactorial, como son las hipótesis relacionadas con dos lesiones cerebrales características de la EA: los ovillos neurofibrilares (NFTs) y placas seniles (Figura 1); y la hipótesis colinérgica [3].

$\mathrm{Al}$ comienzo de los primeros síntomas, principalmente se lleva a cabo el análisis de los biomarcadores relacionados con las dos hipótesis iniciales, como son la proteína Tau y péptido $\beta$-amiloide (A $\beta$ ), respectivamente. Pero aún no se ha determinado con exactitud la etiología para el desarrollo de tratamientos eficaces contra esta enfermedad $[1,4]$.

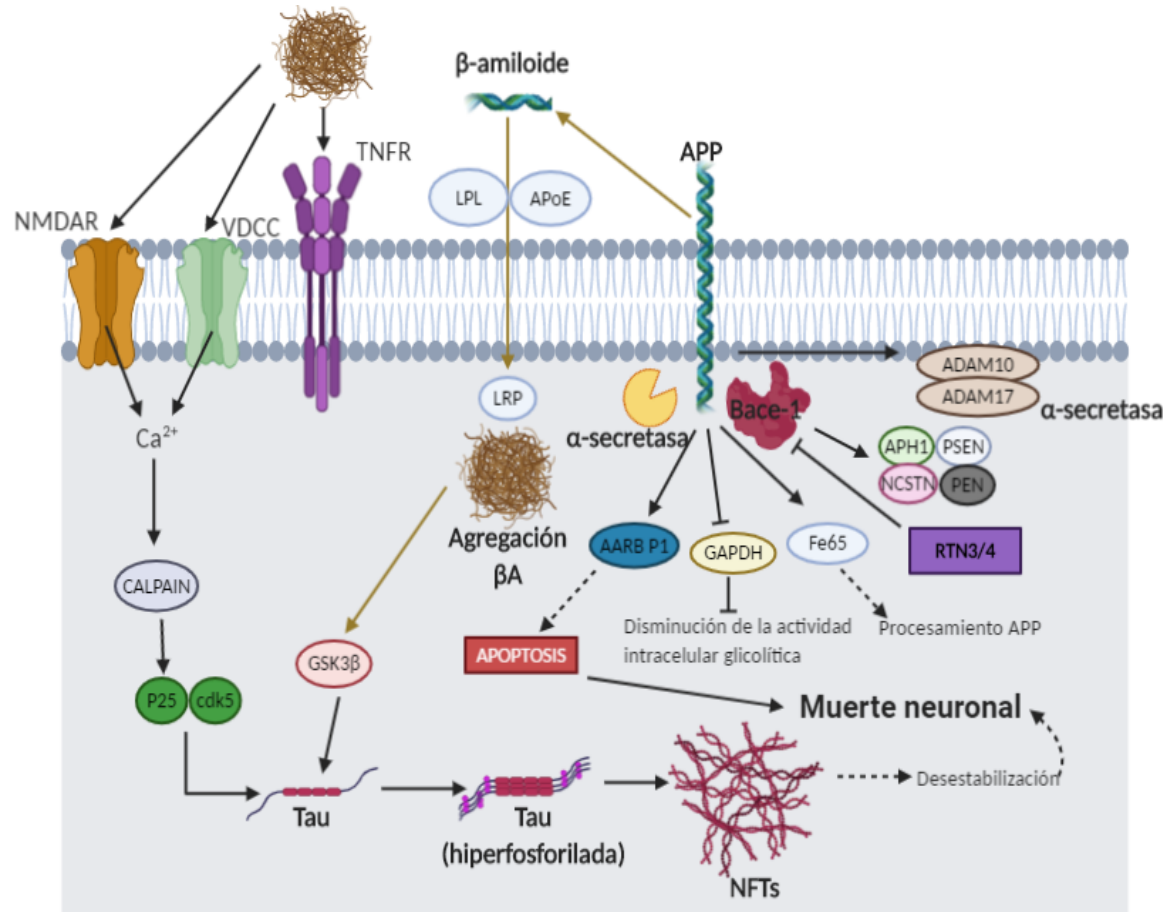

Figura 1: Esquema de las dos hipótesis principales que están involucradas en el desarrollo de la enfermedad del Alzheimer (EA). Hipótesis Tau en el que se produce una hiperfosforilación de la proteína Tau conllevando a su agregación dando lugar a los filamentos neurofibrilares (NFTs). Hipótesis de las placas seniles producidas por la agregación de $\beta$-amiloide $(\mathrm{A} \beta)$, procedente de la proteólisis de la proteína precursora amiloide (APP) llevado a cabo por la enzima $\beta$-secretasa, en especial, BACE-1. Ambos procesos conllevan a una muerte neuronal.

En relación con la hipótesis NFTs, relacionada con la proteína Tau. La proteína Tau interviene en la estabilización de los microtúbulos, contribuyendo a la formación del axón neuronal y tenga lugar la transmisión del impulso nervioso. Tau presenta distintos sitios de fosforilación/desfosforilación para su correcto funcionamiento participando una serie de quinasas (GSK-3 $\beta$ ) y fosfatasas (PP2A) estabilizando o desestabilizando los filamentos de tubulina. Como consecuencia de una hiperfosforilación o inactivación de las fosfatasas provoca una inestabilidad de estos filamentos, provocando que Tau pueda agregarse formando oligómeros neurotóxicos y den origen a los NFTs. Pero no únicamente se ha visto que interviene en EA, sino que participa en otra serie de trastornos proteopáticos [1].

Por otro lado, estaría la hipótesis de las placas seniles, en el que juega un papel el péptido $\beta$ - amiloide (A $\beta)$. $A \beta$ es un fragmento peptídico de 39-43 aminoácidos que procede de la proteólisis de la proteína precursora amiloide (APP). Esta APP es una macromolécula intramembranosa neuronal la cual sufre una proteólisis generalmente por la $\alpha$-secretasa, pero en ocasiones puede estar inducida por $\beta$-secretasa y $\gamma$ secretasa. Una de las principales $\beta$-secretasas que se ha estudiado es BACE-1, llevando a cabo el primer corte de la APP, seguido de la $\gamma$-secretasa [5]. Como consecuencia de una producción excesiva de A $\beta$ provoca que se agregue formando fibras insolubles, las cuales son expulsadas por exocitosis, originando placas extracelulares $[1,3,4]$.

Por último, la hipótesis colinérgica. La acetilcolina (Ach) sintetizada por las neuronas colinérgicas es el principal neurotransmisor cuya actividad se centra en la corteza, ganglio basal y basal cerebro anterior. La colina es el principal sustrato para la síntesis de Ach llevada a cabo por la colina acetiltransferasa, la cual es liberada a la hendidura sináptica provocando la activación de la neurona postsináptica, permitiendo así la transmisión del impulso nervioso. La Ach interviene en funciones esenciales como la neuroplasticidad, conectividad de la red y sincronización de la actividad neuronal. En el caso de haber un exceso de Ach en la hendidura interviene la acetilcolinesterasa que permite el reciclaje de colina. La pérdida colinérgica está relacionada con la degeneración de las neuronas colinérgicas provocado por fallos en los receptores 
nicotínicos y muscarínicos sobre los cuales actúa la acetilcolina, como consecuencia de un exceso de la actividad acetilcolinesterasa o deficiencia en la liberación de Ach [6].

El diagnóstico clínico resulta difícil de determinar, así como su causa, requiriendo una evaluación postmortem del tejido cerebral a través de dos técnicas: fluido cerebroespinal (CSF) y tomografía de emisión de positrones (PET) en combinación con el estudio de biomarcadores mencionados anteriormente [7]. Para su determinación y seguimiento de su evolución a través de un neurólogo analiza cambios en el comportamiento, habilidades y cognitivos, realización de pruebas cognitivas, físicas y neurológicas, análisis de sangre y escaneo cerebral $[2,7]$.

\section{Sintomatología}

El ritmo en el que avanza dicha enfermedad varía según la persona que la padece. Esta patología puede dividirse en una serie de fases en las que según avance dicha enfermedad se van observando distintos síntomas [2].

La primera fase del Alzheimer es la fase leve. Se caracteriza por un deterioro en la memoria episódica en el que se produce olvidos de eventos recientes, desorientación de lo que le rodea, disminución de la concentración y una fatiga más acentuada. A estas personas que se encuentran en esta fase pueden experimentar cambios en el comportamiento, mostrándose inquietas y con ansiedad. Mientras que las habilidades motoras y el habla se mantienen, ya que son capaces mantener una conversación normal.

La segunda fase es moderada, en la que todo aquello relacionado con la memoria empieza a fallar, detectándose alteraciones en el lenguaje, funciones aprendidas y reconocimiento. Presentan dificultades a la hora de comunicarse y de expresarse, necesitan ayuda externa para el desarrollo de procesos cotidianos como vestirse, alimentarse; así como agnosia. Pero esta pérdida no es total, sino que pueden reconocer aún ambientes familiares.

Por último, la fase grave donde los síntomas cerebrales se agravan. Padecen temblores, pudiendo conllevar a tener una crisis epiléptica. Los pacientes que se encuentran dentro de esta fase no reconocen a sus familiares, e incluso puede que no se reconozcan así mismos. Así como se producen incontinencias urinarias y fecales [2].

\section{Dianas terapéuticas}

Ante el gran problema que supone esta patología como se ha expuesto anteriormente, los antecedentes terapéuticos se han enfocado en el tratamiento de una sola hipótesis, teniendo estos fármacos poco éxito. En el presente trabajo se pretende proponer una terapia combinada de ambas hipótesis. A continuación, se analizaron y estudiaron diferentes dianas terapéuticas, así como de sus inconvenientes y se eligieron las dianas más adecuadas para el tratamiento propuesto en este trabajo.

En relación con la hipótesis NFTs, se propuso abordar la diana Tau de diferentes maneras:

En primer lugar, se propuso inhibir la agregación de Tau-P. Para ello, se planteó el diseño de un anticuerpo específico que provocase la eliminación por el propio sistema inmune. Sin embargo, el uso de esta terapia promovería la inflamación del tejido nervioso, pudiendo dañar las neuronas debido a los distintos compuestos liberados durante este proceso fisiológico (citoquinas, quimioquinas), así como a la migración de diversos tipos celulares (macrófagos, linfocitos) que pueden, del mismo modo, causar la destrucción neuronal, por lo que se descartó esta opción.

En segundo lugar, se propuso aumentar la actividad de la fosfatasa de Tau. Evitando de esta manera su agregación y la neurotoxicidad que provoca precipitación de Tau en forma de ovillos neurofibrilares. Sin embargo, esta idea se descartó ante la dificultad de activar una proteína frente a su inhibición, además de ser un método potencialmente inespecífico, pudiendo provocar numerosos efectos secundarios.

Por ello, se decidió que la diana adecuada con respecto a la hipótesis NFTs es GSK-3 $\beta$, para la cual pueden emplearse inhibidores ATP competitivos o no competitivos, siendo éstos últimos los que mejor resultado han ofrecido, además de provocar menos toxicidad y efectos secundarios gracias a su mayor especificidad.

En relación con la hipótesis de las placas seniles, con el fin de evitar la formación de la proteína A $\beta-42$ y su posterior agregación y precipitación se plantearon las siguientes dianas:

Sobreactivación de $\alpha$-secretasa. La cual se descartó como posible diana debido a la complejidad de su activación. Así como de la incertidumbre de que su sobreactivación sea relevante respecto a la actividad de la $\beta$-secretasa a la hora de la formación de los agregados.

Inhibición de la $\gamma$-secretasa. Ya que actúa tanto en la vía amiloidogénica como en la no amiloidigénica, no siendo una buena diana farmacológica en esta patología [8]. 
Por tanto, se llegó a la conclusión de que la diana óptima en este proceso patológico es la $\beta$-secretasa (BACE-1). BACE-1 es responsable del corte específico de APP, generando el péptido A $\beta$ y aumentando sus niveles. Para inactivar esta enzima se plantearon varias opciones. Se planteó el diseño de un anticuerpo específico que provocase la eliminación por el propio sistema inmune, pero como se mencionó anteriormente, esto provoca inflamación neuronal. También se planteó emplear un inhibidor frente a esta enzima, pero la bibliografía muestra numerosos fracasos y la inexistencia de fármacos eficientes contra la actividad de dicha proteasa [9]. Por último, se observó en la bibliografía una proteína que inhibe BACE-1 por interacción directa, el reticulón 3 (RTN-3). Sin embargo, se trata de una proteína que no está muy bien estudiada y todavía se desconoce mucho [10, 11].

Por lo que la idea propuesta fue la síntesis de un péptido análogo a esta proteína que simule al RTN-3, inhibiendo BACE-1. Sin embargo, debido a la imposibilidad de atravesar la barrera hematoencefálica (BHE) por su gran complejidad, se decidió sintetizar péptidos mediante química combinatoria de un tamaño mucho menor (5-30 aa) del dominio de unión de RTN-3 con BACE-1, con el objetivo de que alguno de ellos interaccione con la $\beta$-secretasa modulando su actividad, obteniendo una colección de varios péptidos.

Por lo que, empleando un inhibidor ATP no competitivo de la GSK-3 $\beta$ y un péptido análogo al RTN-3, se atacará tanto a la hipótesis NFTs como a la hipótesis de las placas seniles (Figura 2).

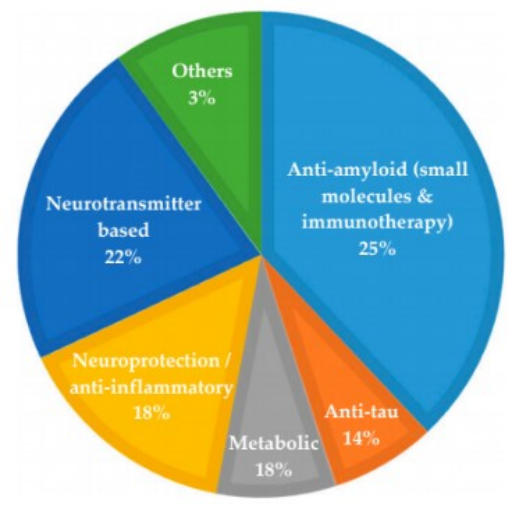

Figura 2. Principales dianas para el tratamiento de la EA.

Cabe mencionar que la enfermedad del Alzheimer es muy compleja y al desconocer el verdadero origen y razón del inicio de la enfermedad, esta terapia combinada pretende evitar cualquier tipo de acúmulo proteico neurotóxico para tratar de mejorar la situación del paciente. Por ello, el objetivo de este trabajo es el desarrollo y demostración de la eficacia de una terapia combinada.

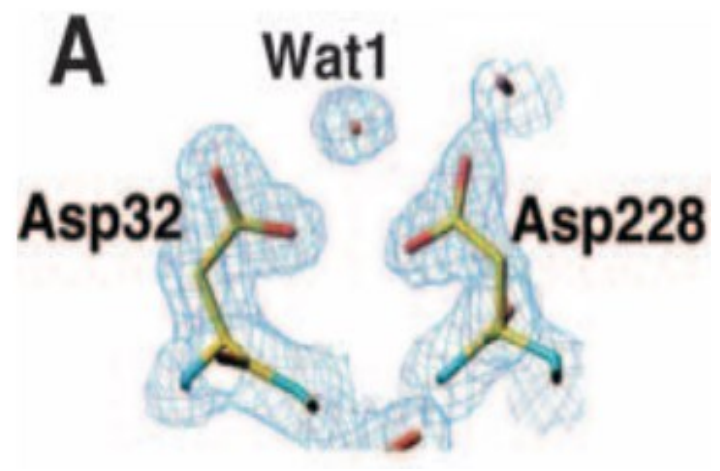

Figura 3. Centro catalítico de BACE-1.

En cuanto a BACE-1 cabe mencionar que es una proteasa cuyo centro activo consta de dos aspárticos los cuales a través de una molécula de agua catalizan el corte de APP (Figura 3) [12].

\section{Diseño del HTS (High Throughput Screening)}

\section{Diseño de péptidos}

Consideramos que la mejor opción es sintetizar un péptido análogo al dominio RHD de RTN-3. Sin embargo, este dominio consta de 235-250 aminoácidos (Figura 4), lo cual un péptido de tamaño completo hace inviable su introducción en un organismo vivo y su éxito terapéutico (no atravesarían la BHE). Por ello, decidimos fragmentar el RHD en péptidos de 20 aminoácidos con la intención de que alguno de ellos interaccione con BACE-1 en su sitio alostérico. 
Se diseñan los péptidos dividiendo el dominio RHD en péptidos de 20 aminoácidos realizando todas las combinaciones posibles alterando el marco de lectura, generando una colección de 250 péptidos.

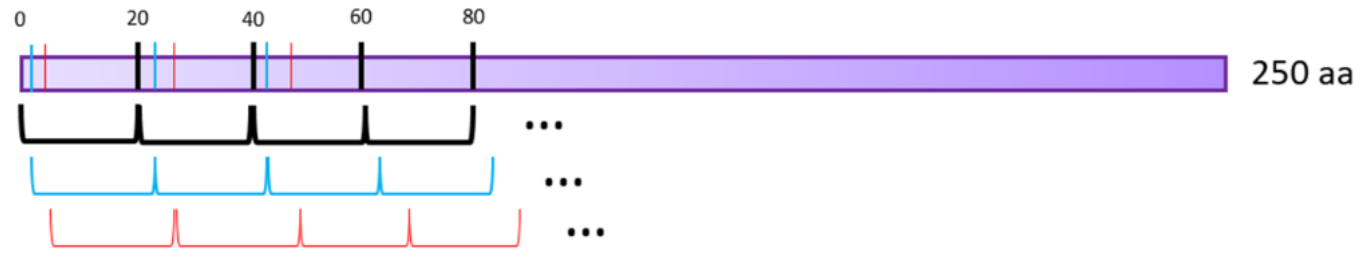

Figura 4: Esquema del dominio RHD y el diseño de péptidos análogos a sintetizar. Se diseñan los péptidos dividiendo el dominio RHD en péptidos de 20 aminoácidos realizando todas las combinaciones posibles alterando el marco de lectura.

\section{Síntesis asistida por polímeros (SOPS)}

La fase sólida (FS) es un polímero insoluble de alto peso molecular, al que se le añade un linker, una molécula que posee un grupo funcional que evita que se agregue el péptido que sintetizaremos a la matriz. Con reacciones sucesivas conseguiremos sintetizar nuestro péptido

Estos péptidos se generarán mediante el método de matriz sólida en disolución, generando los péptidos diseñados de 20 aminoácidos (Figura 5). El método se basa en que la matriz sólida es enorme, un polímero insoluble de alto peso molecular con un cross-linker (molécula) que posee un grupo funcional que evite que se agregue el péptido soluble a la matriz. La primera reacción se basa en aprovechar ese grupo reactivo/funcional del cross-linker para unir éste con el primer aminoácido del péptido que queremos sintetizar. Posteriormente, dependiendo del aminoácido que queramos ir añadiendo y el aminoácido precedente, emplearemos reacciones bien estipuladas en la bibliografía, hasta conseguir nuestro péptido análogo de 20 aminoácidos.

El último paso, se basa en un corte específico para separar el péptido del linker (subida de pH, corte, centrifugación y filtración).

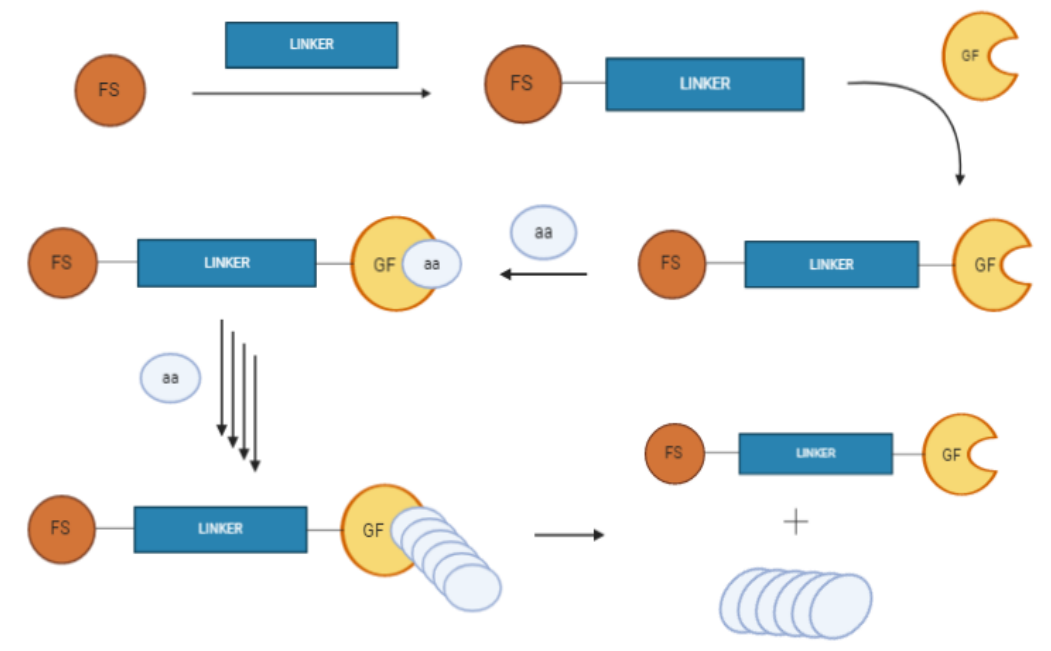

Figura 5: Esquema del proceso de síntesis asistida por polímeros (SOPS). FS: fase sólida. GF: grupo funcional. aa: aminoácido.

\section{Ensayo de Transferencia de energía de resonancia de fluorescencia (FRET)}

Posteriormente, se realizará un ensayo de actividad enzimática mediante análisis de fluorescencia basado en FRET. Se mezclarán en pocillos de placas automatizadas el péptido mimético, la $\beta$-secretasa y la APP, en este orden (Figura 6A). Si el péptido ha tenido éxito en la inhibición de BACE-1, no se generará A $\beta$.

En el ensayo, se aprovechará la capacidad de los llamados tándems de FRET, en los cuales dos compuestos, moléculas o proteínas fluorescentes interaccionan por sus espectros de excitación y emisión: el espectro de emisión de la molécula donadora solapa con el espectro de excitación de la molécula aceptora. En nuestro caso emplearemos el tándem CFP-YFP (cyan y yellow fluorescent protein (CFP y YFP), respectivamente) (Figura 6B).

CFP se excita a $450 \mathrm{~nm}$, emitiendo a $500 \mathrm{~nm}$. Si YFP está cercana, se excitará por solapamiento de los espectros de emisión y excitación de estas proteínas, dándose el fenómeno FRET (transferencia de energía) y emitiendo YFP a $530 \mathrm{~nm}$. 
Se sintetizarán dos tipos de anticuerpos: uno contra el extremo C-terminal de APP y otro específico que reconozca la secuencia de corte reconocida por BACE-1, es decir, que reconozca el sitio de corte específico del péptido (Asp 671). Estos anticuerpos pueden ser obtenidos por varios métodos, como originarse a partir de un animal y purificarse, a partir de vectores de expresión o consultar si existe algún anticuerpo adecuado en el catálogo.

Si el péptido ha tenido éxito inhibiendo a BACE-1, el anticuerpo que reconoce a APP en el sitio de corte se unirá, alterando el color de emisión que observaremos en la fluorescencia (Figura 6B, b1). Si el péptido no ha conseguido inhibir a la enzima, ésta escindirá a APP, no produciéndose el fenómeno de FRET entre ambas moléculas (Figura 6B, b2). De este modo realizaremos un cribado primario de los péptidos de nuestra colección, teniendo nuestros leads. Serían hits, pero hemos decidido no modificarlos ya que consideramos con las pruebas posteriores encontraremos el péptido óptimo que no requiera de modificaciones que, por ejemplo, aumenten su solubilidad, y que además podrían afectar su unión con BACE-1.

A)

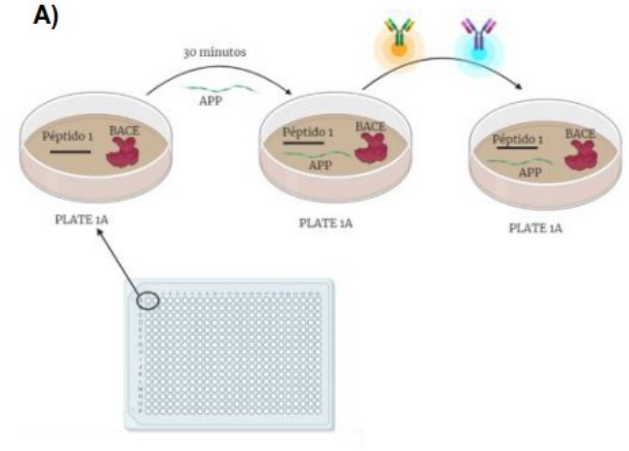

B) b1

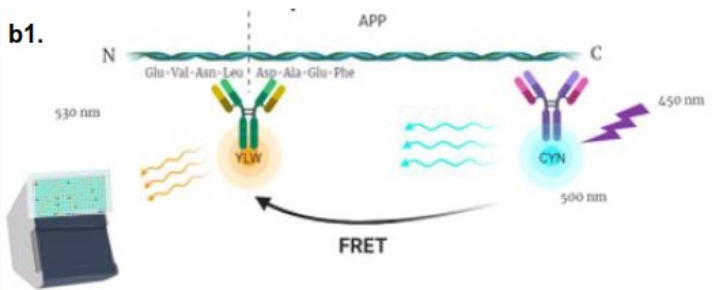

b2.

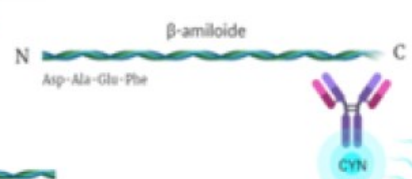

$\mathrm{N}$
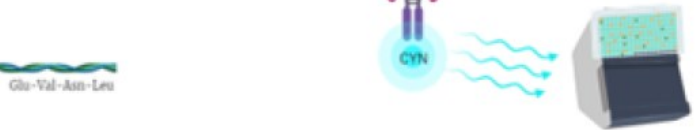

Figura 6: Esquema y representación del ensayo de FRET. A) Se muestran los componentes de la reacción en cada pocillo de la placa. B) Funcionamiento del fenómeno y emisión de colores en cada caso; b1. péptido inhibidor y b2. péptido no inhibidor. BACE: $\beta$-secretasa; APP: proteína precursora amiloide; anti-CYN: anticuerpo Cyan, reconoce el C-terminal de APP; Anti-YLW: anticuerpo Yellow, reconoce el sitio de corte de BACE-1.

\section{Ensayo PAMPA/ Transwell}

Para evaluar la capacidad de los péptidos seleccionados de atravesar la BHE (Figura 7) (solubilidad y permeabilidad), se diseñan ensayos PAMPA/ Transwell simulando la BHE In vitro (Figura 7B), mediante el cultivo de células de varios tipos (endoteliales, pericitos y astrocitos) separadas en dos compartimentos [13]. El ensayo se basa en medir la cantidad de péptido de cada tipo que ha sido capaz de pasar al compartimento inferior.

A)

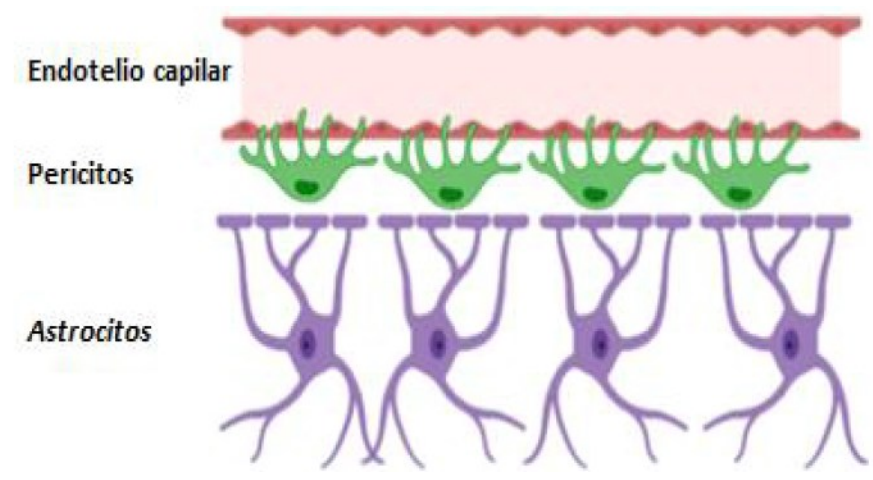

B)

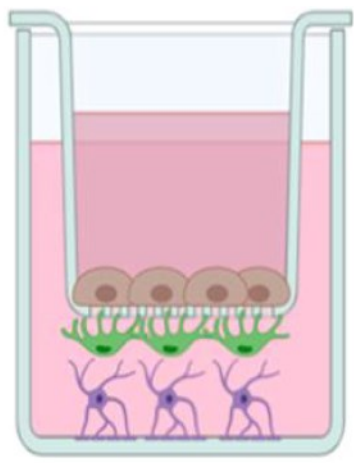

Figura 7: Representación esquemática de la barrera hematoencefálica (BHE). A) In vivo y B) In vitro.

En este ensayo PAMPA/Transwell se evaluarán distintos métodos para mejorar la solubilidad y permeabilidad de los péptidos por sí solos:

En uno de ellos, se evaluará si el recubrimiento de los péptidos con liposomas recubiertos de transferrina (descubiertos en el MIT en 2019) mejora el tropismo por la BHE, así como el paso a su través (Figura $8 \mathrm{~B})$. En el otro, se añadirá el péptido recubierto con una proteína priónica que mejore el tropismo por el cerebro (Figura 8C) 
A)

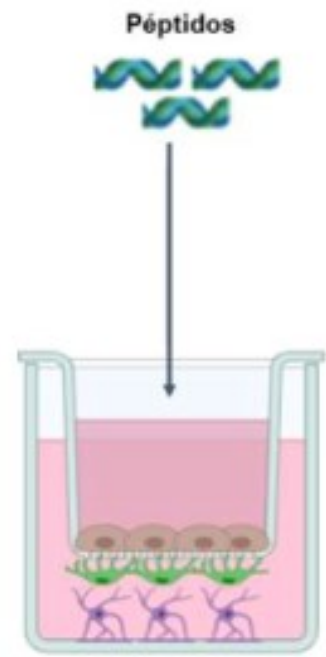

B)

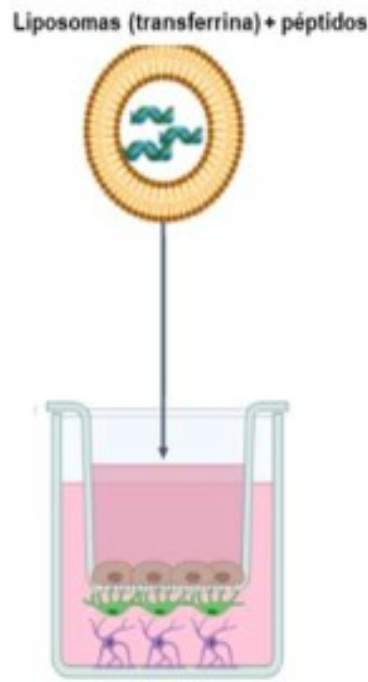

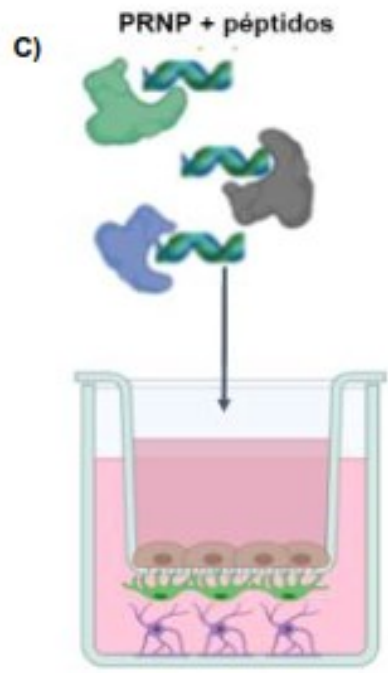

Figura 8: Métodos a testar en el ensayo PAMPA/ Transwell para medir la solubilidad de los péptidos análogos. A) Péptidos, B) Liposomas recubiertos de transferrina con los péptidos en su interior y C) Proteína priónica unida a los péptidos análogos

\section{Ensayos celulares}

El siguiente paso consistirá en realizar los ensayos celulares. Nuestro interés radica en emplear una línea de neuronas humanas que sobreexpresen APP. La línea elegida es la SH-SY5Y (Figura 9), una línea comercial estable de neuronas dopaminérgicas humanas provenientes de neuroblastoma [15]. La sobreexpresión de APP se logrará mediante la transfección con lentivirus y la introducción de un vector cuya expresión sea inducible por tamoxifeno (Figura 10).

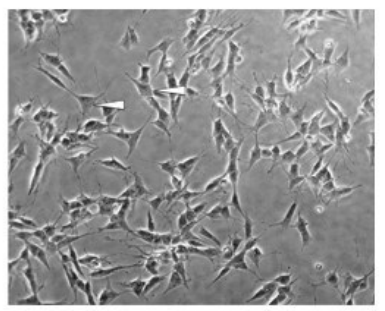

Figura 9: Línea comercial de neuronas dopaminérgicas humanas SH-SY5Y

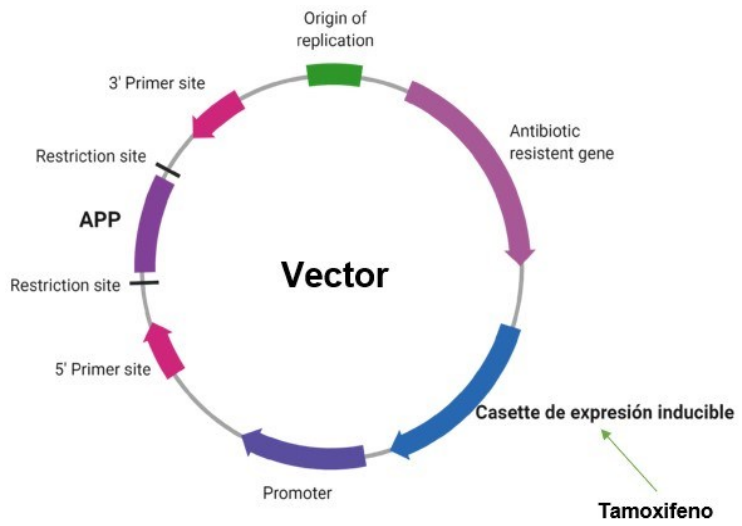

Figura 10: Vector de expresión inducible por tamoxifeno

Tras seleccionar aquellos péptidos que han tenido actividad inhibidora de BACE-1, se realiza el mismo ensayo celular con la línea anteriormente empleada, pero añadiendo el inhibidor de GSK-3 $\beta$ y añadiendo

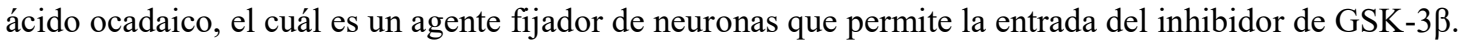

Este ensayo es necesario para seleccionar los péptidos que realmente posean sinergia con el inhibidor de GSK-3 $\beta$ y no produzcan un efecto antagónico.

En los ensayos realizados en estas neuronas, emplearemos los Quantum Dots, nanopartículas con un núcleo de zinc y cadmio que nos permitirán observar los niveles de APP, Tau y p-Tau (Figura 11). Para ello, se conjugará un anticuerpo a estas partículas mediante una proteína linker y se medirá por microscopía confocal la fluorescencia obtenida. Se seleccionarán aquellos péptidos en los cuales se observe un aumento de APP y Tau, y que provoquen una disminución de p-Tau. Además, se realizarán 
Western-Blots complementarios para medir los niveles de Tau soluble e insoluble de manera cualitativa y para comprobar los datos obtenidos.

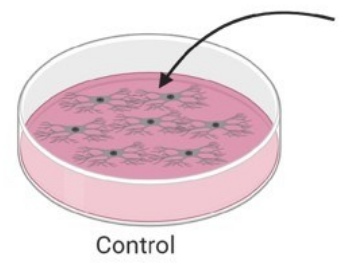

Péptido

Inhibidor GSK-3 $\beta$

Péptido + Inhibidor GSK-3ß

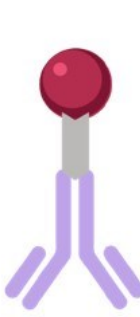

APP

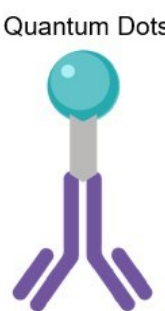

p-Tau

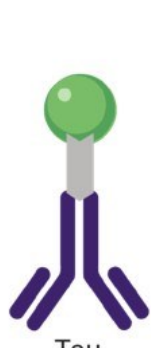

Tau

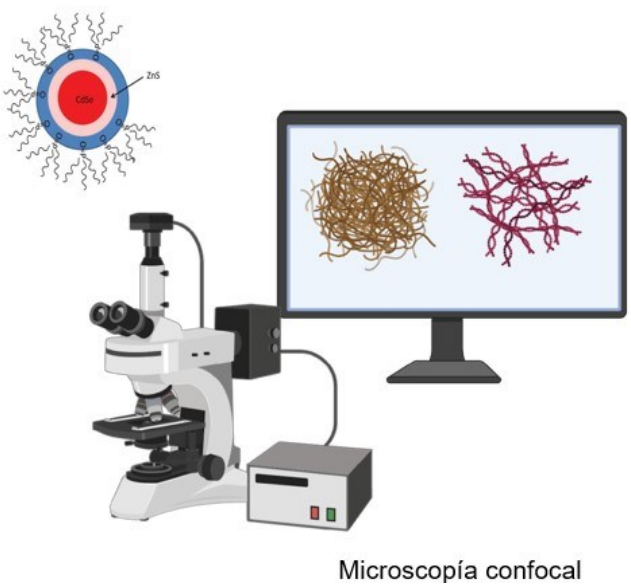

Figura 11: Representación esquemática del uso de los Quantum Dots. Se utilizan 3 Quantum Dots acoplados a un anticuerpo específico para APP, Tau y p-Tau. Los Quantum Dots se añaden a cada una de las condiciones del ensayo celular: grupo control, grupo de péptidos leads, grupo con inhibidor GSK-3 $\beta$ y grupo con el inhibidor GSK-3 $\beta$ y cada uno de los leads. Los resultados se observarán posteriormente mediante microscopía confocal.

\section{Ensayos animales}

Posteriormente, se realizarán ensayos en animales de experimentación para comprobar la toxicidad y efectividad de los leads seleccionados. Para ello se escogerá el modelo de ratón APP23 (APP-Tg mouse model), el cual es un modelo comercial capaz de expresar el APP humano de manera inducible [14]. Con el empleo de los Quantum Dots frente a APP, Tau y p-Tau, se analizarán los niveles de dichas proteínas tras introducir la mezcla del inhibidor de GSK-3 $\beta$ y el péptido mimético de RTN-3, de manera oral o intravenosa.

Asimismo, para favorecer la absorción de los péptidos y el paso por la barrera hematoencefálica, se recubrirán los mismos con liposomas asociados a transferrina o con PRNP en función de los resultados en el ensayo PAMPA/Transwell, formando un complejo con tropismo por el tejido nervioso.

Durante todo el periodo del ensayo en animales, se les realizarán ensayos de comportamiento para observar cómo van desarrollando la enfermedad hasta que se les introduce los distintos compuestos y, posteriormente observar cómo evolucionan. Entre los diferentes estudios de comportamiento, se valorará la memoria mediante el Test de laberinto acuático (MWMT) y el movimiento mediante el Test de campo abierto.

Posteriormente, se sacrificarán los animales y se analizará su corteza cerebral utilizando los QD, observando el efecto in vivo de la terapia combinada previo al ensayo clínico en humanos de fase I.

\section{Resultados esperados}

Los resultados que esperamos obtener son tanto a corto como a largo plazo.

A corto plazo esperamos inhibir la formación tanto de ovillos neurofibrilares (NFTs) como de placas amiloides mediante terapia combinada y poder demostrar la efectividad de la terapia "multi-target".

A largo plazo, esperamos paliar los efectos de pérdida de memoria y neurodegeneración progresivos característicos de la enfermedad de Alzheimer así cómo llegar a mejorar la calidad de vida de los pacientes.

\section{Agradecimientos}

En primer lugar, agradecer a la Universidad de Alcalá, y en particular, a los profesores del Máster en Dianas Terapéuticas en Señalización celular, así como a los conferenciantes que han hecho posible la realización de este trabajo. Especial mención a Alberto Domingo, Ana Bajo y Carlota Tosat, cuya ayuda ha sido imprescindible en la realización de este trabajo.

\section{Referencias}

1. Liyanage SI, Weaver DF. 2019. Misfolded proteins as a therapeutic target in Alzheimer's disease. Adv Protein Chem Struct Biol, 118: 371-411 
2. 2016. 2016 Alzheimer's disease facts and figures. Alzheimers Dement, 12(4): 459-509

3. Kumar A, Singh A, Ekavali. 2015. A review on Alzheimer's disease pathophysiology and its management: an update. Pharmacol Rep, 67(2): 195-203

4. Villegas S. 2015. Enfermedad de Alzheimer: nuevas estrategias terapéuticas. Medicina Clínica, 145(2): 76-83

5. Chlebek J, De Simone A, Hostalkova A, Opletal L, Perez C, Perez DI, et al. 2016. Application of BACE1 immobilized enzyme reactor for the characterization of multifunctional alkaloids from Corydalis cava (Fumariaceae) as Alzheimer's disease targets. Fitoterapia, 109: 241-7

6. Hampel H, Mesulam MM, Cuello AC, Farlow MR, Giacobini E, Grossberg GT, et al. 2018. The cholinergic system in the pathophysiology and treatment of Alzheimer's disease. Brain, 141(7): 1917-33

7. Hane FT, Robinson M, Lee BY, Bai O, Leonenko Z, Albert MS. 2017. Recent Progress in Alzheimer's Disease Research, Part 3: Diagnosis and Treatment. J Alzheimers Dis, 57(3): 645-65

8. Maia MA, Sousa E. 2019. BACE-1 and gamma-Secretase as Therapeutic Targets for Alzheimer's Disease. Pharmaceuticals (Basel), 12(1):

9. Knopman DS. 2019. Lowering of Amyloid-Beta by beta-Secretase Inhibitors - Some Informative Failures. N Engl J Med, 380(15): 1476-8

10. Chiurchiu V, Maccarrone M, Orlacchio A. 2014. The role of reticulons in neurodegenerative diseases. Neuromolecular Med, 16(1): 3-15

11. Sharoar MG, Yan R. 2017. Effects of altered RTN3 expression on BACE1 activity and Alzheimer's neuritic plaques. Rev Neurosci, 28(2): 145-54

12. Shimizu H, Tosaki A, Kaneko K, Hisano T, Sakurai T, Nukina N. 2008. Crystal structure of an active form of BACE1, an enzyme responsible for amyloid beta protein production. Mol Cell Biol, 28(11): 3663-71

13. Wong AD, Ye M, Levy AF, Rothstein JD, Bergles DE, Searson PC. 2013. The blood-brain barrier: an engineering perspective. Front Neuroeng, 6(7): 1-22

14. Sasaguri H, Nilsson P, Hashimoto S, Nagata K, Saito T, De Strooper B, et al. 2017. APP mouse models for Alzheimer's disease preclinical studies. EMBO J, 36(17): 2473-87

15. SH-SY5Y Cell Line. En ATCC. https://www.lgcstandards-atcc.org/Products/All/CRL2266.aspx?geo_country=fr 